\title{
Composites of Styrene-butadiene Block-copolymers Reinforced with WEEE Polystyrene Fraction
}

\author{
RAMONA MARINA GRIGORESCUㄹ, PAUL GHIOCA ${ }^{1 *}$, LORENA IANCU ${ }^{1}$, MADALINA ELENA GRIGORE ${ }^{1}$, RAMONA ELENA ANDREI', \\ RODICA MARIANA ION ${ }^{1,2}$, CRISTIAN ANDI NICOLAE ${ }^{1}$, RALUCA GABOR ${ }^{1}$ \\ ${ }^{1}$ National Institute for Research \& Development in Chemistry \& Petrochemistry - ICECHIM, 202 Splaiul Independentei, 060021, \\ Bucharest, Romania \\ ${ }^{2}$ Valahia University of Târgoviste, Institute of Multidisciplinary Research for Science and Technology, 13 Aleea Sinaia, 130004, \\ Targoviste, Romania
}

\begin{abstract}
The high global production of electric and electronic equipment increases in the same manner the amount of the waste that needs to be recycled. Special attention is given to the plastics recycling from the waste in addition to the metals recovery that brings economic advantages. Considering that the plastic amount contains about $80 \%$ polystyrene polymers, the paper presents a recycling study of this fraction as reinforcing agent for a styrene-butadiene block copolymer. In order to reduce the melt viscosity, some of the composites were extended with paraffin-naphthenic "heavy white oil". The blends were characterized by mechanical testing, thermal and dynamo-mechanical analysis. Based on the resulted properties, it can be concluded that the extended and reinforced composites can be used as material for shoe soles.
\end{abstract}

Keywords: WEEE recycling, styrene-butadiene block-copolymer, WEEE polystyrene fraction, extended composites, paraffinic oil, reinforcing effect

Electric and electronic equipmenthad a major segment of the global production in the last decades, overtaking even the automotive industry [1]. As a result of this particularly high production, the amount of the waste of electrical and electronic equipment (WEEE) increased at the same measure [1, 2], leading to an intense concern of researchers to recovery and recycling of both the metallic component and the majority polymeric fraction. Considering that polystyrene and its copolymers (acrylonitrile-butadiene-styrene ABS, high-impact polystyrene HIPS) represent about $80 \%$ from the total recovered polystyrene fraction $[3,4]$, the researches focused on the individual and collective recycling of these components [5-9].

Individual mechanical recycling with and without compatibilizer or impact-strength modifiers has been the most extensively studied method because it is a costeffective and easily achieved [10, 11]. Polymers thus processed show superior properties only in the case of advanced separation of polymer assortments [8], which is difficult to achieve by using the current separation methods.

The mechanical recycling in the melt state of binary mixtures (ABS, HIPS) or of the total polystyrene copolymers without additional components leads to materials with modest physical-mechanical properties. These composites are however used in the production of items that do not require special performance properties such as clothes hangers, plates, organizing boxes, water collection tanks [11, 12].

An important method to recover the WEEE plastics consists in their use as additives in concrete and bitumen especially for road coverings [1, 10, 13-15].

In order to diversify the use domain of the polystyrene fraction in its entirety, the paper presents the study regarding the replacement of the polystyrene used as reinforcing material of styrene-butadiene block-copolymers leading to composites with good thermoplastic processability. These composites are the basis for the production of shoe soles injected directly onto the footwear and of the insulating casings of electrical cables that require high malleability.

\section{Experimental part}

Materials and methods

The reinforcing study was achieved using a star styrenebutadiene block-copolymer (SBS D1184 CM supplied by Kraton) with a $30 \%$ polystyrene content and a molecular mass of $270.000 \mathrm{~g} / \mathrm{mole}$ (determined by GPC).

The polystyrene fraction used as reinforcing agent was separated from WEEE by extraction at room temperature using tetrahydrofuran (THF) as solvent. The dissolved fraction represents about $78 \%$ of the total collected polymers and had the following composition: PSt $10 \%$, ABS $48 \%$, HIPS $15 \%$, other polymers $5 \%$.

In order to reduce the melt viscosity, some of the composites were extended with paraffin-naphthenic heavy white oil with the characteristics presented in Table 1. An important fact to mention is that the paraffin-naphthenic oil is incompatible with the polystyrene phase, being distributed only in the polybutadiene phase where it acts as an extender [16-18].

Table 1

CHARACTERISTICS OF THE EXTENDER OIL

\begin{tabular}{|c|l|c|}
\hline Nr. crt. & \multicolumn{1}{|c|}{ Property } & Values \\
\hline 1. & Color & Colorless \\
\hline 2. & Density at $25^{\circ} \mathrm{C}, \mathrm{g} / \mathrm{cm}^{3}$ & 0.867 \\
\hline 3. & Refraction index at $25^{\circ} \mathrm{C}$ & 1.4740 \\
\hline 4. & Average molecular weight, $\mathrm{g} / \mathrm{mole}$ & 418 \\
\hline 5. & Kinematic viscosity at $38^{\circ} \mathrm{C}, \mathrm{m}^{2} / \mathrm{h}$ & 0.134 \\
\hline 6. & Structural composition, \% & 66.6 \\
& C paraffinic & 29.9 \\
& C naphthenic & 3.5 \\
& C aromatic & \\
\hline
\end{tabular}


The reinforcement study of styrene-butadiene block copolymers (SBS) with the WEEE polystyrene fraction was performed in the tetrahydrofuran extraction solution at a total polymer concentration of $20-25 \%$. The dosing of the extension oil was maintained constant at $25 \%$. The polystyrene fraction was dosed in steps of $5 \%$ until $30 \%$, the maximum limit being imposed by maintaining the polybutadiene as the continuous phase of the composite material $[19,20]$. The desolventation of mixtures was achieved by centrifugal casting at $50-60{ }^{\circ} \mathrm{C}$ to obtain composite films of about $1 \mathrm{~mm}$ thickness. The removal of residual solvent from the films was carried outin a vacuum oven at $60^{\circ} \mathrm{C}$. The films thus obtained were used to the physical-mechanical and thermal characterization of the composites.

The tensile properties were determined using a FPZ100 dynamometer at a stretching speed of $500 \mathrm{~mm} / \mathrm{min}$, on specimens stamped from the tested films, according to SR EN ISO 527-96.

The composites hardness was achieved using a Shore hardness durometer, model PosiTector SHD-A, DeFelsko, USA.

The glass transition temperature $(T)$ of the materials was determined using a DSC Q2000 Calorimeter (TA Instruments). The method parameters were: Modulation $\pm 1.06{ }^{\circ} \mathrm{C}$ every $40 \mathrm{~s}$, Helium - purged gas with $50 \mathrm{ml} / \mathrm{min}$., Ramp $10^{\circ} \mathrm{C} / \mathrm{min}$ to $300^{\circ} \mathrm{C}, 100 \mathrm{\mu L} \mathrm{T}_{\text {zero }}$ Aluminium pan.

The dynamic mechanical analysis' (DMA) was achieved using a Q800 V20.24 DMA instrument (TA Instruments), in air atmosphere, with $1 \mathrm{~Hz}$ frequency, at $-105 \div 155^{\circ} \mathrm{C}$, and speed of $5^{\circ} \mathrm{C} / \mathrm{min}$. Storage modulus (E2), loss modulus (E22) and Tan ä temperature dependence was recorded.

Thermal stability was analyzed by thermogravimetric analysis (TGA) using a Q5000IR instrument (TA Instruments). Method: 1) Ramp $10^{\circ} \mathrm{C} / \mathrm{min}$ to $700^{\circ} \mathrm{C}$; 2) Select gas 2; 3) Isothermal for 5 min; purge gas 1: Nitrogen; purge gas 2: Air; sample pan: Platinium 100 $\mathrm{LL}$.

\section{Results and discussions}

The polystyrene fraction solubilized from WEEE added into the styrene-butadiene block-copolymer is not compatible with the polybutadiene continuous phase although some copolymers (ABS, HIPS) contain small polybutadiene sequences, as evidenced by the practically constant Tg values of the polybutadiene phase, according to the data presented in Table 2. The component polymers of the polystyrene fraction have a much higher molecular weight than the polystyrene blocks components of SBS, being thus incompatible [21-23] and distributed as separate domains in the continuous polybutadiene phase.

The $\mathrm{Tg}$ increase for the polystyrene phase with the dosage of WEEE fraction (Table 2, fig. 1) is due to the higher energy necessary for the Tg transition of polymers with superior molecular mass.

The DMA analysis of extended and non-extended styrene-butadiene block copolymer composites highlights the existence of two distinct vitreous transitions at about 108 and $125^{\circ} \mathrm{C}$ for non-extended samples, respectively 96 and $128^{\circ} \mathrm{C}$ for oil extended samples (figs. 1 and 2). Taking into account that the polymers $\mathrm{Tg}$ increases with the molecular weight, the first transition corresponds to the polystyrene domains with a low molecular weight $(20.000$ $\mathrm{g} /$ mole) components of SBS and the second transition is attributed to the mixture of WEEE polystyrene polymers with molecular weight higher than $100.000 \mathrm{~g} / \mathrm{mole}$. This thermal behavior confirms the incompatibility of the polystyrene blocks of SBS with the polystyrene fraction of WEEE.

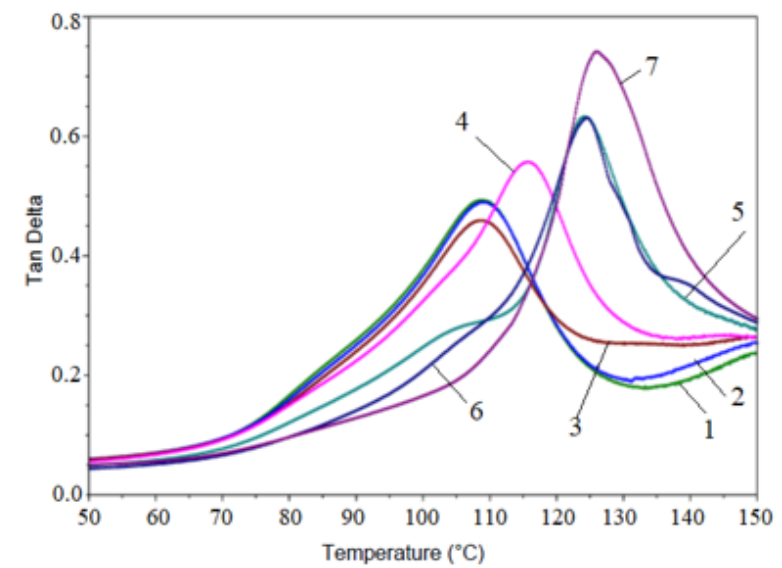

Fig. 1. Variation of Tan Delta for non-extended SBS composites (1-SBS; 2-SBS-5\% WEEE; 3- SBS-10\% WEEE; 4- SBS-15\% WEEE; 5-

SBS-20\% WEEE; 6- SBS-25\% WEEE; 7- SBS-30\% WEEE)

Table 2

GLASS TRANSITION TEMPERATURE (Tg) DETERMINED BY DSC FOR THE REINFORCED SBS

\begin{tabular}{|c|c|c|}
\hline Dosage, \% & $\begin{array}{c}\text { Tg of polybutadiene } \\
\text { phase, }{ }^{\circ} \mathrm{C}\end{array}$ & $\begin{array}{c}\text { Tg of } \\
\text { polystyrene } \\
\text { phase, }{ }^{\circ} \mathrm{C}\end{array}$ \\
\hline 0 & -94.2 & 86.4 \\
\hline 5 & -94.1 & 89.2 \\
\hline 10 & -94.3 & 93.8 \\
\hline 15 & -94.2 & 97.5 \\
\hline 20 & -94.3 & 98.6 \\
\hline
\end{tabular}

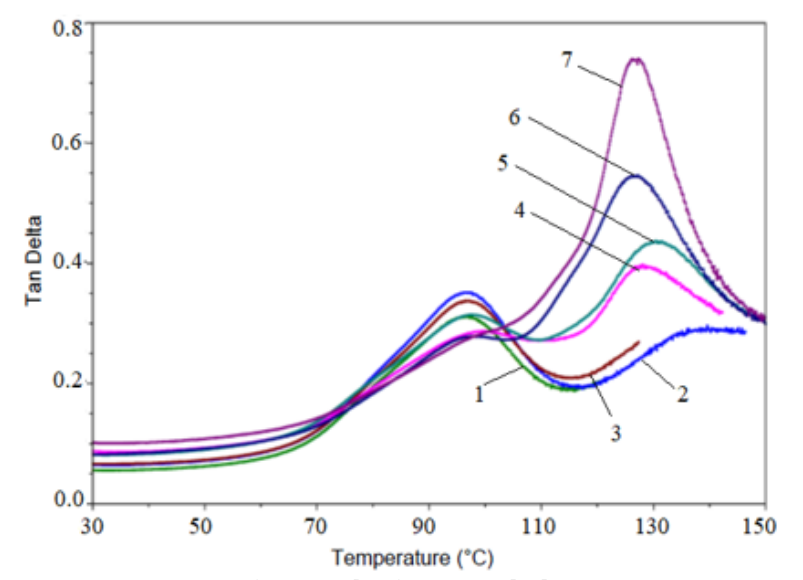

Fig. 2. Variation of Tan Delta for extended SBS composites, containing 25\% paraffin-naphthenic oil (1-SBS; 2-SBS-5\% WEEE; 3- SBS-10\% WEEE; 4- SBS-15\% WEEE; 5- SBS-20\% WEEE; 6- SBS-25\% WEEE; 7- SBS-30\% WEEE)

The Tg decrease of the elastomer blocks extended with paraffin-naphthenic oil indicates a partial presence in this phase of aromatic hydrocarbons from the oil that have a higher compatibility with the polystyrene phase. The high molecular weight of styrene copolymers from WEEE makes difficult to detect the presence of this small fraction fragmented.

Un-modifying the polystyrene network formed by the block components of SBS ensures the maintenance of the vulcanized elastomer properties of the composites, the recovered polystyrene fraction playing only the role of unreactive reinforcing filler.

The reinforcement effect of the polystyrene fraction recovered from WEEE is similar to that of the virgin 
polystyrene $[20,24]$ and is exhibited by the decrease in tensile strength and elongation atbreak, more pronounced at its first dosages, as can be seen from Figures 3 and 4 . The more pronounced decrease of these properties at the first doses of polystyrene blend is due to the more significant reduction of the entanglement in this first reinforcement phase. At higher dosage, entanglement is less affected, the dispersion of the polystyrene fraction being achieved especially by increasing the particle volume to the detriment of increasing their number [25], so that the modifying effect on these parameters is more attenuated.

The reinforcement effect produced by the WEEE recovered polystyrene fraction on the styrene-butadiene block-copolymer increases in intensity with this fraction dosage for both the oil-free elastomer and the extended composite, as can be seen from the variation of the storage modulus (figs. 5 and 6) and the loss modulus (figs. 7 and 8).

The hardness of the styrene-butadiene block-copolymer composites is presented in figure 9. The linear increase with the polystyrene fraction dosage follows the rule of two non-reactive components blend, as expected.

According to literature, the materials generally used in producing shoe soles have to presents as main average mechanical properties [26, 27]:

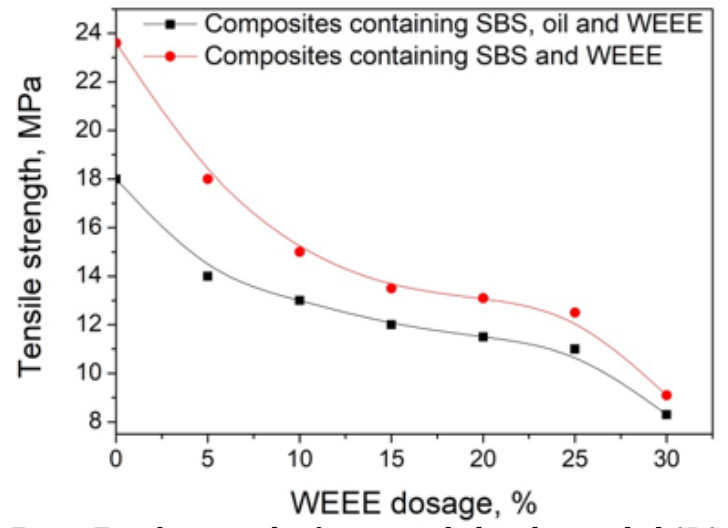

Fig. 3. Tensile strength of un-extended and extended SBS composites

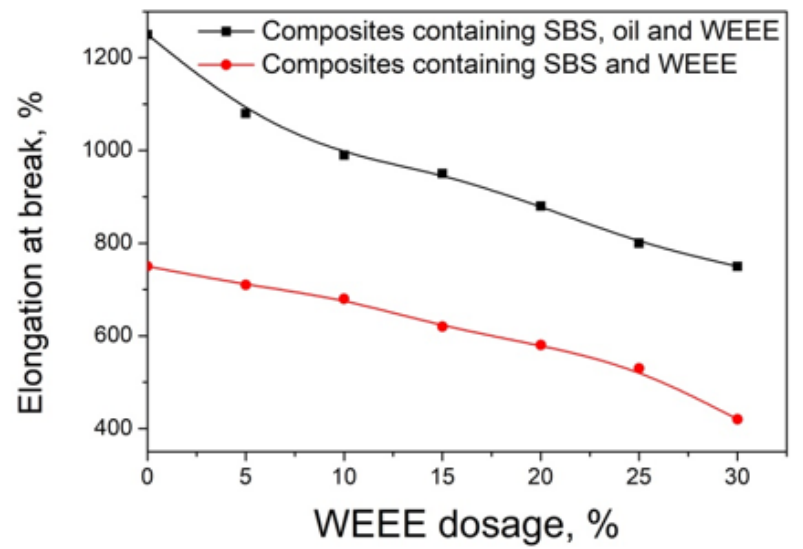

Fig. 4. Elongation at break of un-extended and extended SBS composites

-Tensile strength: 5 -10 MPa;

-Elongation at break: $600-700 \%$ (up to $1000 \%$ for sport shoes);

-Hardness: 50 - 80 Shore A.

Analyzing the variation of mechanical properties depending on the WEEE recovered polystyrene fraction, it can be seen that the styrene-butadiene block-copolymer extended with $25 \%$ paraffin-naphthenic oil and reinforced with $15-25 \%$ polystyrene waste corresponds in terms of mechanical properties for use as masterbatch for the

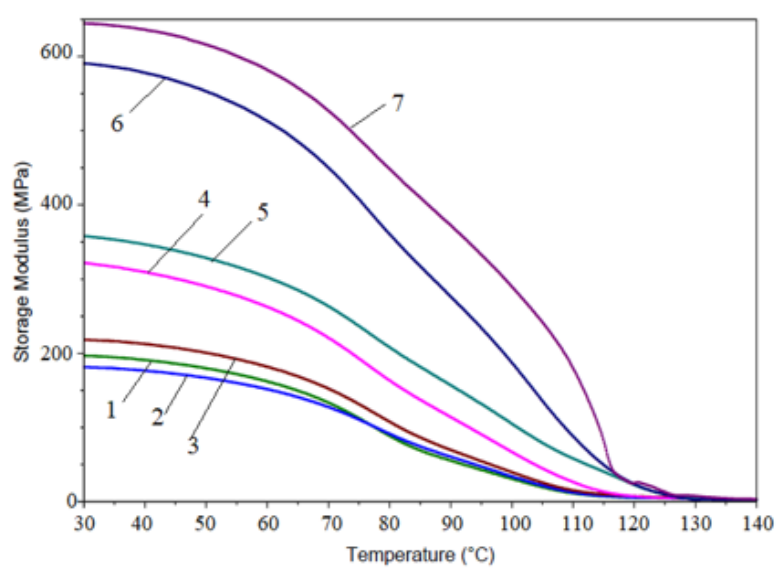

Fig. 5. Variation of the Storage Modulus for non-extended SBS composites (1-SBS; 2-SBS-5\% WEEE; 3- SBS-10\% WEEE; 4- SBS-15\% WEEE; 5- SBS-20\% WEEE; 6- SBS-25\% WEEE; 7- SBS-30\% WEEE)

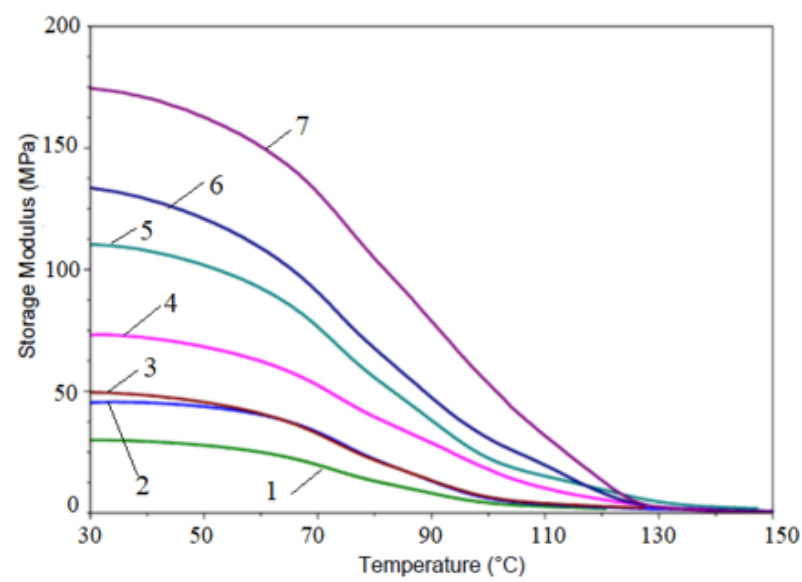

Fig. 6. Variation of the Storage Modulus for extended SBS composites, containing 25\% paraffin-naphthenic oil (1-SBS; 2-SBS5\% WEEE; 3- SBS-10\% WEEE; 4- SBS-15\% WEEE; 5- SBS-20\% WEEE; 6- SBS-25\% WEEE; 7- SBS-30\% WEEE)

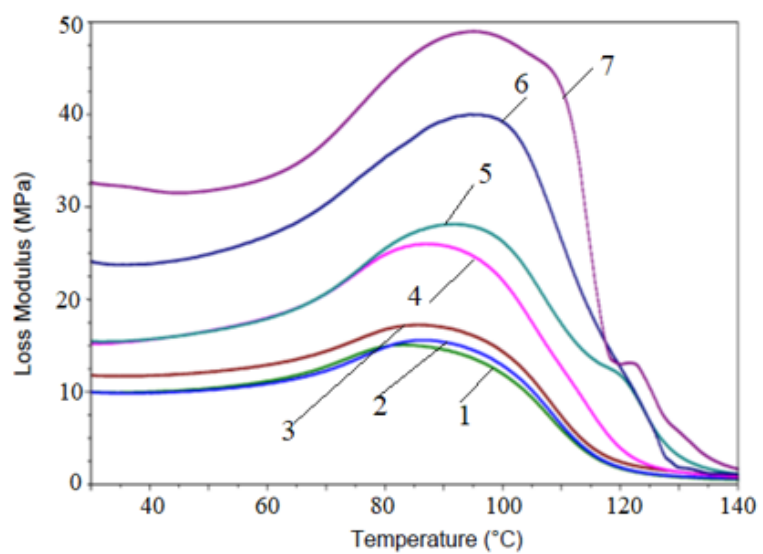

Fig. 7. Variation of the Loss Modulus for non-extended SBS composites (1-SBS; 2-SBS-5\% WEEE; 3- SBS-10\% WEEE; 4- SBS-15\% WEEE; 5- SBS-20\% WEEE; 6- SBS-25\% WEEE; 7- SBS-30\% WEEE)

production of shoe soles. Special attention is paid to sports footwear, due to its good adhesion, especially to wet paving and synthetic sports coverings.

\section{Conclusions}

The study of obtaining and characterization the styrenebutadiene block copolymers composites reinforced with WEEE polystyrene fraction has established the incompatibility of this polymer blend with the polystyrene block components of the elastomer. The mixture of polystyrene polymers disperses as domains in the 


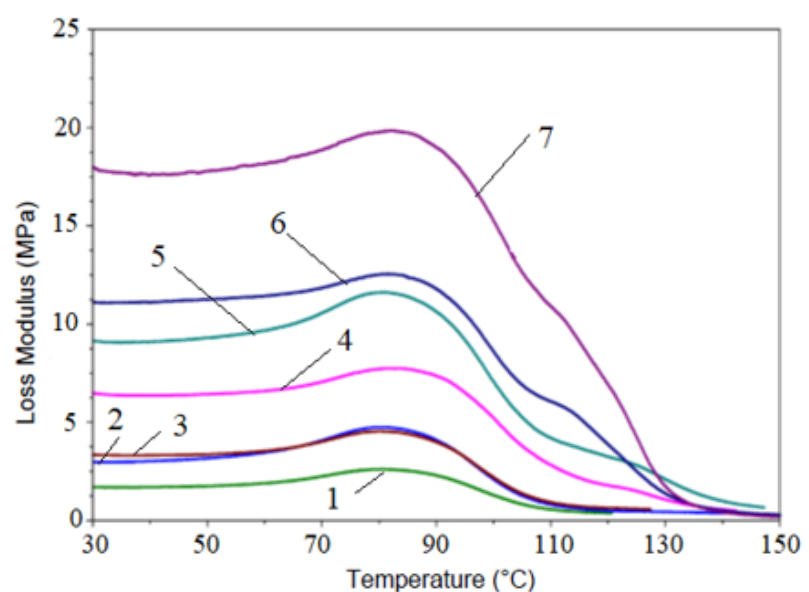

Fig. 8. Variation of the Loss Modulus for extended SBS composites, containing $25 \%$ paraffin-naphthenic oil (1-SBS; 2-SBS5\% WEEE; 3- SBS-10\% WEEE; 4- SBS-15\% WEEE; 5- SBS-20\% WEEE; 6- SBS-25\% WEEE; 7-SBS-30\% WEEE)

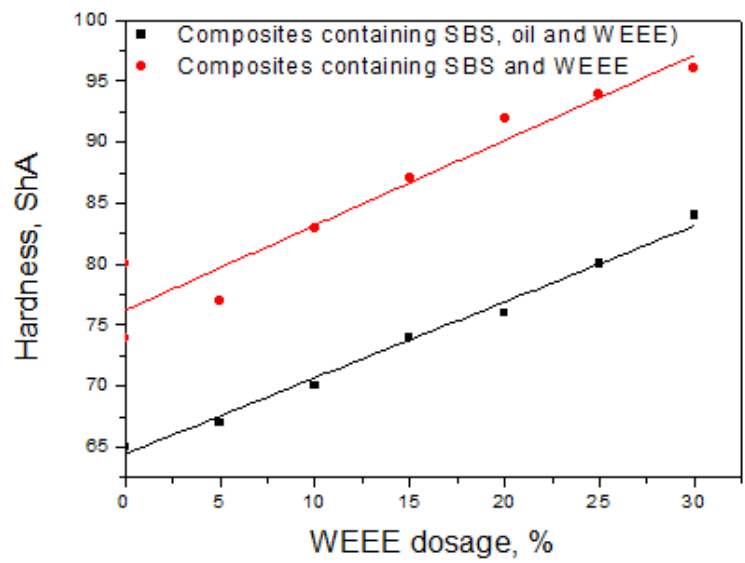

FIg. y. Hardness of un-extended and extended SBS composites

continuous polybutadiene matrix, acting as inactive filler with a strong reinforcement effect.

The composites extending with $25 \%$ oil (reported only for SBS) was necessary in order to improve the melt processing of composites by significantly reducing their melt viscosity.

The composites based on styrene-butadiene blockcopolymer extended with $25 \%$ paraffin-naphthenic oil and containing $15-25 \%$ polystyrene fraction recovered from WEEE lead to the production of composite materials that can be used as material for shoe soles that can be injected directly onto the footwear.

Acknowledgments: This paper was supported by a grant of the Romanian Ministery of Research and Innovation, CCCDI -UEFISCDI, projectnumber PN-III-P1-1.2-PCCDI-2017-0652 / 84 PCCDI/2018, within PNCDI III and by project no. PN.19.23.02.01.04, contract no. 23N/2019 within the Nucleu Program.

\section{References}

1.BUEKENS, A., YANG, J., J. Mater Cycles Waste Manag.,16, 2014, p. 415.

2.KIDDEE, P., NAIDU, R., WONG, M.H., Waste manag., 33, 2013, p. 1237.

3.STENVALL, E., Licentiate of engineering Chalmers University of Technology: Gothenburg, Sweden 2013.

4.GRIGORESCU, R.M., GRIGORE, M.E., GHIOCA, P., IANCU, L., NICOLAE, C.A., ION, R.M., TEODORESCU, S., ANDREI, E.R., Mat. Plast., 56, 201, p. 77.

5.TOSTAR, S., Doctor of philosophy Chalmers University of Technology: Gothenburg, Sweden, 2016.

6.VAZQUEZ,Y.V., BARBOSA, S.E., Waste Manag., 53, 2016, p. 196.

7.VAZQUEZ,Y.V., BARBOSA, S.E., Waste Manag., 59, 2017, p. 403.

8.VAZQUEZ,Y.V., BARBOSA, S.E., J. Environ. Manage., 217, 2018, p. 381.

9.HIRAYAMA, D., SARON, C., Polymer, 135, 2018, p. 271.

10.GUO, J., GUO, J., WANG, S., XU, Z., Environ Sci Technol, 43, 2009, p. 503.

11.HASAN, M.R.M., COLBERT, B., YOU, Z.P., JAMSHIDI, A., HEIDEN, P.A., HAMZAH, M.O., Constr. Built. Mater., 110, 2016, p. 79.

12.ADAM, A.P., GONCALVES, J., ROBINSON, L.C., da ROSA, L.C., SCHNEIDER, E.L. MATER. RES. IBERO AM. J., 20, 2017, p. 202.

13.PERRIN, D., MANTAUX, O., IENNY, P., LÉGER, R., DUMON, M., LOPEZ-CUESTA J -M., Waste Manag., 56, 2016, p. 438.

14.MANTAUX, O., LORRIOT, T., CHIBALON, L., AURREKOETXEA, J., PUERTO, A., AROSTEGI, A., URRUTIBEASCOA, I., J. Mater. Sci. Tehnol., 20, 2004, p. 125.

15.MOHD HASAN, M.R., COLBERT, B., YOU, Z., JAMSHIDI, A., HEIDEN, P.A., HAMZAH, M.O., Constr. Built. Mater., 110, 2016, p. 79.

16.HOLDEN, G., In Applied plastics engineering handbook: processing and materials, Kutz M. (Ed.) William Andrew INC: Norwich, NY, USA, 2011.

17.UTRACKI, L.A., WILKIE, C., Polymer Blends Handbook; Springer Netherlands, 2014.

18.HOLDEN, G., KRICHELDORF, H.R., QUIRK, R.P., Thermoplastic Elastomers; Hanser Publishers, 2004.

19.SATAPATHY, B.K., LACH, R., WEIDISCH, R., SCHNEIDER, K., JANKE, A., KNOLL, K., Eng. Fract. Mec., 73, 2006, p. 2399.

20.GHIOCA, P., GRIGORESCU, R.M., IANCU, L., SPURCACIU, B., NICOLAE, C.A., GABOR, A.R., Mat. Plast., 55, no. 1, 2018, p. 14. 21.KOIZUMI, S., HASEGAWA, H., HASHIMOTO, T., Macromol. Symp., 62,1992, p.75.

22.KOIZUMI, S., HASEGAWA, H., HASHIMOTO, T., Macromolecules, 27, 1994, p. 6532.

23.SU, B., ZHAO, Y.S., CHEN, F., FU, Q., Chinese J. Polym. Sci., 33, 2015, p. 964.

24.ZHOU, J., DU, X., YUE, W., Proceedings of 4th International Conference on Renewable Energy and Environmental Technology (ICREET 2016), Atlantis Press, 2017.

25.HOLDEN, G., In Recent Advances in Polymer Blends, Grafts, and Blocks, Sperling LH. (Ed.) Springer US: Boston, MA, 1974, p. 269.

26.BULBUL, S., AKCAKALE, N., GOKMESE, H., GOK, O., YASAR, M., Int. Adv. Res. Eng. J., 1, 2017, p. 1.

27.J OLENE, F.S., NUNES, R.C.E., Rheological Behavior of Mineral Fillers in Shoe Soles Composites, Universidad Federal do Rio de Janeiro P.O Box 68525 Rio de Janeiro, RJ, Brazil (2000).

Manuscript received: 27.06 .2019 